\title{
Research on the current situation and countermeasures of public health personnel deployment in a prefecture-level city in Jiangxi Province
}

\author{
Zhan Xingxin ${ }^{1} \mathrm{a}^{*}, \mathrm{Hu} \mathrm{Lu}^{1}$, Yang Rui ${ }^{1}$, Li Hui ${ }^{1}$, Lin Zhi ${ }^{1}$, Li Xiaojun ${ }^{1}$ \\ 1. School of public health, Xinyu Univeristy, Xinyu Jiangxi, 338004, P.R.China \\ a*gnyzxx18@163.com
}

\begin{abstract}
Objective: To explore the corresponding measures based on the analysis of the current status and problems of public health staffing of the CDC in a prefecture-level city, so as to provide some references for improving the ability of local CDCs to respond to public health emergencies. Methods: In order to understand the current status of domestic public health personnel of a prefecture-level city, the study conducted the qualitative interviews and literature research as well as consulting statistical data yearbook. Results: The total number of health personnel in the CDC of a prefecture-level city was small, and the aging trend was obvious; the health personnel of the CDC had a lower level of education, fewer masters and doctors, and fewer personnel with senior professional titles. Qualitative results showed that there was a general shortage of talents in CDC, and the staffing rate of the CDC was significantly lower than the national standard, especially the low proportion of highly educated talents. Conclusions: Improving the current situation of public health talents at grass-roots CDCs should enhance the training of high-level applied public health talents, and improve the configuration of grass-roots disease control instruments and equipment, and increase the reserve of grass-roots disease control technology; strengthen investment in information network construction, and establish and improve the three-level disease prevention and control network construction.
\end{abstract}

Keywords: Centers for Disease Control and Prevention; Public health personnel; Current deployment; Countermeasures

\section{江西省某地级市疾控中心公共卫生人员配置现状及对 策研究}

占星新 ${ }^{1 a^{*}}$, 胡露 ${ }^{1}$, 杨瑞 ${ }^{1}$, 李晖 ${ }^{1}$, 林治 ${ }^{1}$, 黎小军 ${ }^{1}$

1. 新余学院, 公共卫生与健康学院, 江西, 新余, 338004;

a*gnyzxx18@163.com

\section{摘要}

目的: 本研究在分析某地级市疾病预防控制中心公共卫生人员配置现状和问题的基础上提出相应的措施, 为地 方性疾控中心应对突发公共卫生事件的能力提供一些参考。方法: 通过文献研究和统计数据年鉴了解国内公共 卫生人员现状, 开展定性访谈了解某地级市公共卫生人员配置现状。结果: 某地级市疾病预防控制中心卫生人 员总量少, 老龄化趋势明显; 疾控中心卫生人员学历层次较低, 硕博士人才较少, 且拥有高级职称人员较少; 定性结果显示, 疾控机构普遍人才短缺, 疾控中心人员配备率明显低于国家标准, 尤其是高学历人才比例低。 结论: 改善基层疾控中心公共卫生人才配置现状应提升高水平应用型公共卫生人才的培养力度; 完善基层疾控 的仪器设备配置, 增强基层疾控的技术力量储备; 加强信息网络建设投入, 建立健全三级疾病预防控制网络建 设。 
关键词: 疾病预防控制中心; 公共卫生人员; 配置现状; 对策

\section{1. 前言}

疾病预防控制体系作为公共卫生体系的重要组 成部分, 在应对突发重大公共卫生事件中有着主力军 和专业支撑的地位。地方性疾控中心公共卫生人才数 量及质量是决定地方健康和公共卫生体系应对突发 公共卫生事件能力高低的关键性因素 ${ }^{[1]}$ 。本研究旨在 了解某地级市疾病预防控制中心的公共卫生人员配 置现状, 并提出相应应对措施, 旨在提高地方突发公 共卫生事件的应对能力。

\section{2. 研究方法}

\section{1 文献研究及卫生统计年鉴}

通过查询国内外各期刊网站、中国卫健委网站、 江西卫健委网站收集相关的研究文献。统计数据均来 自于《某市疾病预防控制中心 2018 年年鉴》和《某 市统计年鉴》。

\section{2 定性访谈}

\subsection{1 访谈对象}

根据定性调查目的性抽样, 抽取能够为研究问题 提供最大信息量的研究对象。于 2020 年 7 月在江西 省某地级市疾病预防控制中心 2 名主要管理人员进 行个人深入访谈。

\section{3 资料收集方法}

采用半结构式深入个人访谈法, 事先拟定访谈纲 要, 以开放式提问的方式来收集信息资料。访谈纲要 主要包含以下问题: (1)简单描述一下当前贵单位公共 卫生人员的现状。(2)与国家要求公共卫生人员配置现 状差距。(3)导致这种现状的原因及对策

访谈地点选择在疾控中心的会议室, 并且保证会 议室的房间安静, 根据事先拟定好的访谈提纲, 对访 谈对象就疾控人员配种现状等进行深入访谈。访谈开 始前, 由主持者介绍访谈目的、访谈内容和访谈匿名 性, 在得到被访谈者的准许后, 由记录员协助, 全程 进行录音。每个访谈时间在 30-50 分钟。

\section{4 资料的整理和分析}

首先组织两人对访谈录音进行文字转录, 转录文字
利用定性分析软件 Nvivo v 8.0 进行主题框架法分析, 提炼出文稿所反应的主题。定性分析的研究结果有助 于研究者更深入地理解量性研究的结果。

\section{3. 研究结果}

3. 1. 某地级市疾控中心卫生人员总量少, 老龄化趋 向明显。2019 年该疾控中心编制 45 人, 在职在岗人 员 45 人, 其中男 27 人, 占 $60 \%$, 女 18 人, 占 $40 \%$ 。 35 岁及以下 9 人, 占 $20 \% ; 36^{2} 40$ 岁 7 人, 占 $15.5 \%$; 人, 占 $17.8 \%$; 中专 4 人, 占 $8.9 \%$; 高中及以下 2 人, 占 $4.4 \%$ 。其中专业技术人员 40 人 $41^{2} 45$ 岁 7 人, 占 $15.5 \% ; 51^{\sim} 54$ 岁 9 人, 占 $20 \% ; 55$ 岁及以 上 9 人, 占 $20 \%$ 。

3. 2 . 某地级市疾控中心卫生人员学历层次较低, 拥 有高级职衔人员较少。研究生 6 人, 占中心人员总数 $13.3 \%$; 大学本科 25 人, 占 $55.6 \%$ 。其中高级职称 10 人, 占专业技术人员总数 $25 \%$, 中级 21 人, 占 $46.7 \%$ 。

3. 3. 定性访谈结果。某地级市疾病预防控制中心普 遍人才短缺, 地级市以下如县/区级基层疾控机构人 才短缺现象尤为显著。部分疾控机构从业人员为护理 等其他非公共卫生专业人员, 具备公共卫生领域专业 知识的卫生人员数量不足。政府对疾控机构的财政投 入不足, 疾控中心卫生人才的待遇较低, 招聘高学历 人才难, 并且内部人才流失严重。同时指出, 疾控机 构属于受益慢、周期长、投资大, 需要卫生行政部部 门对疾控工作的大力支持。

\section{4. 讨论}

\section{1. 疾控中心人员配备率明显低于国家标准, 专业人才缺口大}

该市 2019 年常住人口 119 万, 此外还有大量流动 人口, 该市辖一县四区, 共有卫生机构 1194 个, 其 中医院 14 个, 社区卫生服务中心（站） 27 个, 妇幼 保健院（所、站） 3 个, 疾病预防控制中心 (防疫站) 3 个, 卫生监督所 (中心) 3 个, 诊所及其他 115 个。 2018 年初共有卫生技术人员 6835 人，专业公共卫生 机构 750 人, 人均 6.41 人/万（低于全国平均 6.93 人/万）, 疾病预防控制中心 76 人, 人均 0.65 人/ 万（低于国家标准 1.75 人/万）。数据显示, 该市专 
业公共卫生机构人员配备率，尤其是疾控中心人员配 备率明显低于国家标准，专业人才缺口大。且该市疾 控中心卫生人员老龄化趋势明显, 青中老年不能进行 有效衔接。

\section{2. 疾控中心公共卫生人员总量不足和人才 流失严重, 尤其是高学历人才比例低}

公共卫生属于专业领域, 为保证疾病的预防和控制, 对职员素质要求较高 ${ }^{[2]}$ 。近年来, 疾控机构加强对高 学历人才的引进, 但地方经济发展相对落后, 政府对 疾控机构的财政投入不足, 卫生人员待遇低，导致对 外招聘高学历人才难, 对内人才流失严重, 因此高学 历人才占比依然较低。

\section{3. 疾控中心存在护理等非公共卫生专业从 业现象, 专业性人才急需补充。}

定性访谈结果显示, 仍有部分护理等其他专业人员 从事公共卫生领域, 虽可在一定程度上缓解公共卫生 人力资源不足的问题, 但其所具备的专业知识无法满 足中国人民日益增进的公共卫生需求 ${ }^{[3]}$, 急需补充专 业性的公共卫生人才。

\section{5. 相关对策}

\section{1. 提高疾控中心人员的薪资待遇}

有研究表明, 影响基层公共卫生人才队伍稳定性 的重要因素是薪资待遇。待遇过低是疾控机构对外人 才招聘难、对内人才流失严重的主要原因之一。为吸 引留住公共卫生人才, 保持公共卫生人员队伍的稳定 性, 政府应加大对疾控机构的财政扶持力度, 制定政 策切实提高公共卫生人才薪资待遇 ${ }^{[4]}$ 。与此同时制定 相应的激励政策, 如完善人员的晋升和考核制度, 有 效提高公共卫生人员工作的积极性, 进而使公共卫生 人员更高效率、高质量的完成工作任务 ${ }^{\left[{ }^{[5]}\right.}$ 。

\section{2. 加大高水平应用型公共卫生人才的培养 力度}

政府应引导鼓励地方本科院校开设公共卫生和 预防医学及其相关专业, 扩大公共卫生领域硕士和专 升本的招生规模, 不断完善公共卫生人才培养方案, 加强对公共卫生人才培养力度, 从而为地方性疾控机 构提供更多高学历、高层次和实用型人才 ${ }^{[6]}$ 。同时注 重开展对在职公共卫生人员的继续教育, 包括中短期 进修、学历教育、学术论坛、专题讲座、专业标准化 训练等多种形式 ${ }^{[7]}$ 。

\section{3. 完善基层疾控的仪器设备配置, 增强基层 疾控的技术力量储备}

加强投入基层疾控机构的仪器设备, 满足基层疾
控工作需求, 仪器设备的合理配置, 是基层疾控顺利 开展工作的基础, 进一步促进基层疾控中心的健康、 可持续发展 ${ }^{[8]}$ 。邀请专家定期开展对基层疾控的技术 指导和培训, 提高基层公共卫生人才的应用与研究能 力，增强基层疾控的技术力量储备 ${ }^{[9]}$ 。

\section{4. 加强信息网络建设投入, 建立健全三级疾 病预防控制网络建设}

2020 年新冠疫情暴露出疾控机构在信息网络建 设存在诸多方面的不足。应加强信息网络建设的投入， 通过整合现有资源，构建信息平台共享信息，建立国 家、省、市三级疾病监测与业务管理数据库, 进一步 优化传染病监测、健康风险因素监测、疾病预防控制 综合管理、中国流感监测信息系统等综合信息管理系 统, 实现各级疾控机构统一规划、统一平台、统一管 理 ${ }^{[10]}$ 。同时注意加强信息网络系统安全的建设工作, 根据实际工作分配权限，增强工作人员的信息安全意 识 ${ }^{[11]}$ 。

\section{6. 结论}

综上所述, 改善基层疾控中心公共卫生人才配置 现状应提升高水平应用型公共卫生人才的培养力度; 完善基层疾控的仪器设备配置, 增强基层疾控的技术 力量储备; 加强信息网络建设投入, 建立健全三级疾 病预防控制网络建设。

\section{项目基金}

本项目由江西省教育厅科技项目 “基于 mHealth 的社区老年高血压患者自我管理干预研究，编号： GJJ171078” ; “江西省社会科学规划项目 “江西省 基层疾控预测预警能力现状研究及对策, 编号: 20SH17”； 2021 年度江西省卫生健康委员会科技计 划项目 “江西省疾控中心公共卫生人才配置现状及 对策研究 (202131061) ”资助。

\section{References}

[1] Ch. Wang, Z.Q. Liu, Zh.D. Guan. Challenges faced by China's CDCs and their countermeasures: an analysis based on the survey data from six provinces. Chinese Journal of Medical Management Sciences, 2020,10(01):10-14

[2] J.L. Du, J.N. Xu, Y.L. Shi, et al. Analysis of Human Resources and Guarantee Status of Jiangsu Disease Prevention and Control Institutions[J].Soft Science of Health, 2020, 34(10):28-32.

[3] K.He, T.X. Wei, W.Y. Jin, et al. Analysis on the Public Health Human Resource Allocation in Community Health Service Centers of Hongkou 
District, Shanghai[J].Chinese Primary Health Care, 2019,33(08):17-20.

[4] K.M. Song, X.F. Jiang, Y.W. Liu, et al.The job preferences of primary care providers in China[J].Chinese Journal of Health Policy, 2012,5(03):12-16.

[5] Y.L. Meng, A.Y. Mao, Y.J. Yang,et al.Analysis on the current status of public health staffing in Beijing from 2011 to $2016[\mathrm{~J}]$.Soft Science of Health, 2019, 33(03):42-47.

[6] X.J. Cui, X.Y. Gen, K.G. Wang, et al. Analysis on the current situation and fairness of human resource allocation in disease prevention and control institutions in Shandong Province[J].Soft Science of Health, 2020,34(01):59-64.

[7] Sh.W. Zhuang, Y.N. Li.Study on the analysis and prediction of the current situation of the allocation of health human resources in Guangxi villages and towns[J].Soft Science of Health,2020,34(02):51-55.

[8] Y.F. Zhang. Status and Suggestions of Occupational Health Technology Service in the Grass-rooted Disease Control Center[J].China Health Industry, 2018, 15(05):178-179.

[9] Ch.Y.Li,Y.Wang, M.Sun, et al.Performance assessment for provincial disease control and prevention system( 14) : the technical guidance to the primary level was highly emphasized, but the application research needed to be improved[J].Chinese Health Resources,2012,15(02):103-105.

[10] J. Lv, F.Sh. Chang,Ch.Y. Li, et al. Performance assessment for provincial disease control and prevention system( 11) : information management has been strengthened, but information network needs urgent improvement $[\mathrm{J}]$.Chinese Health Resources,2012,15(02):97-98+102.

[11] J. Ma. Discussion on the Security Construction Strategy of the Information Network System of the Center for Disease Control and Prevention[J].China Management Informationization, 2019,22(06):167-168. 